Keywords: Glycolate, Ion Chromatography

Retention: Permanent

\title{
Anion Analyses by Ion Chromatography for the Alternate Reductant Demonstration for the Defense Waste Processing Facility
}

D. R. Best

August 2010

Savannah River National Laboratory Savannah River Nuclear Solutions Aiken, SC 29808

Prepared for the U.S. Department of Energy under contract number DE-AC09-08SR22470.

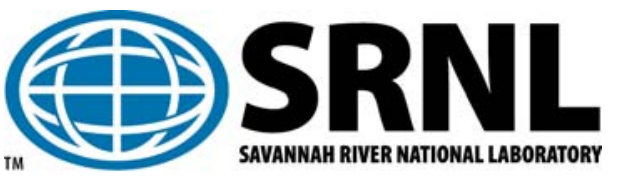


SRNL-STI-2010-00389

Revision 0

\section{DISCLAIMER}

This work was prepared under an agreement with and funded by the U.S. Government. Neither the U.S. Government or its employees, nor any of its contractors, subcontractors or their employees, makes any express or implied:

1. warranty or assumes any legal liability for the accuracy, completeness, or for the use or results of such use of any information, product, or process disclosed; or

2. representation that such use or results of such use would not infringe privately owned rights; or

3. endorsement or recommendation of any specifically identified commercial product, process, or service.

Any views and opinions of authors expressed in this work do not necessarily state or reflect those of the United States Government, or its contractors, or subcontractors.

\section{Printed in the United States of America \\ Prepared for \\ U.S. Department of Energy}




\section{REVIEWS AND APPROVALS}

AUTHORS:

D.R. Best, Engineering Process Development

Date

TECHNICAL REVIEW:

R. E. Eibling, Engineering Process Development

Date

APPROVAL:

A. B. Barnes, Manager

Date

Engineering Process Development

S.L. Marra, Manager

Date

Environmental \& Chemical Process Technology Research Programs

J. E. Occhipinti, Manager

Date

SRR Engineering 


\section{TABLE OF CONTENTS}

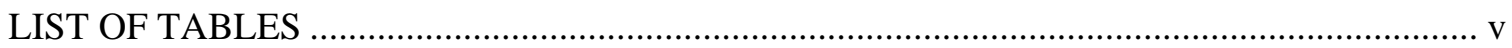

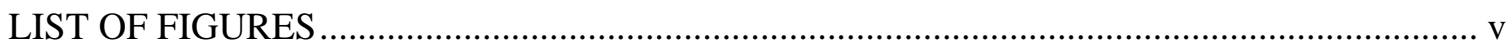

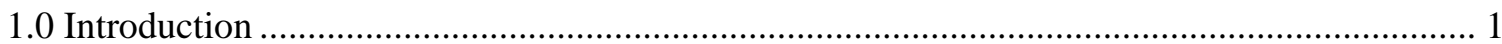

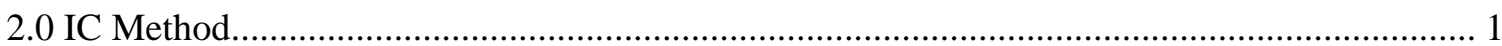

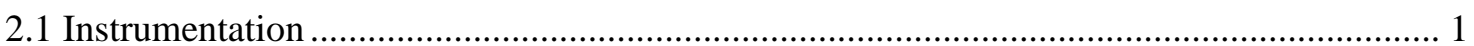

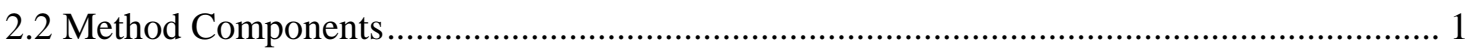

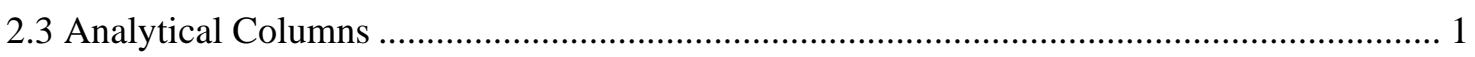

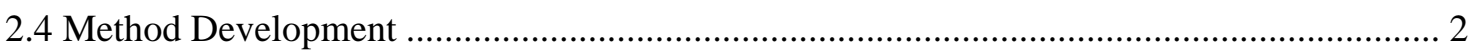

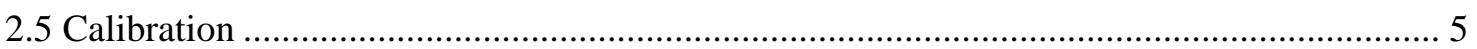

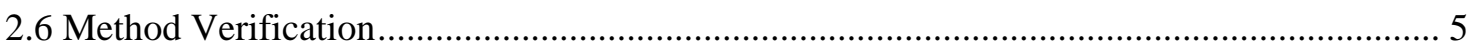

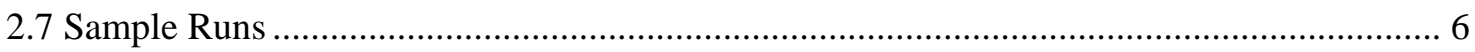

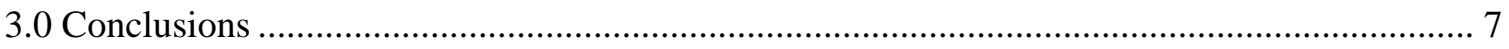

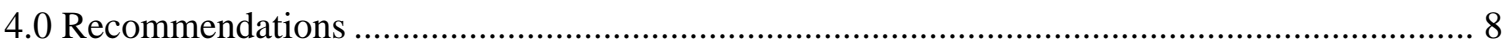

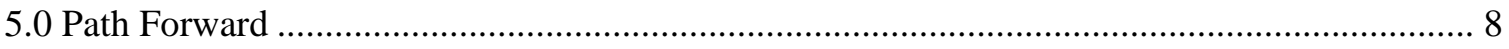

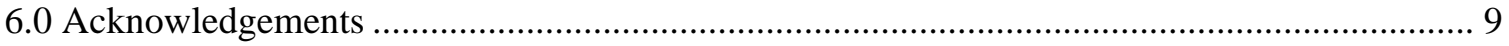




\section{LIST OF TABLES}

Table 2-1 Initial Successful Gradient Method.......................................................................... 3

Table 2-2 Successful Microbore Gradient Method ..................................................................... 4

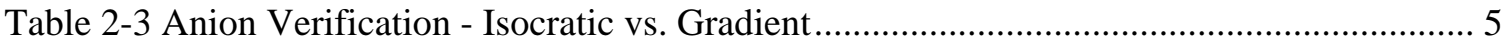

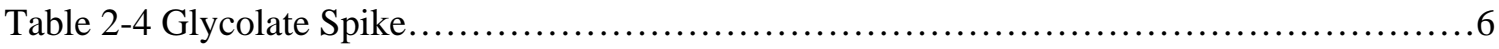

Table 3-1 Final Ion Chromatography Method for Glycolate and Other Anions ............................ 7

\section{LIST OF FIGURES}

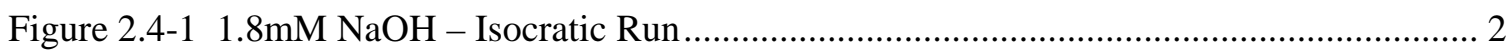

Figure 2.4-2 Gradient Method 1 - Ramped in Stages ............................................................... 3

Figure 2.4-3 Gradient Method 2 - Microbore System - Ramped Increments ............................... 4

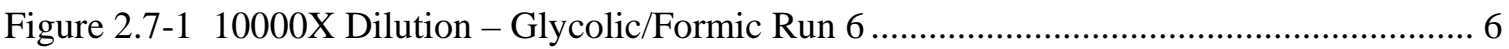

Figure 2.7-2 500X Dilution - Glycolic/Formic Run 6 ............................................................. 7 


\section{LIST OF ABBREVIATIONS}

ACTL Aiken County Technology Laboratory

$\mathrm{AD}$

Analytical Development

DWPF Defense Waste Processing Facility

HC High Capacity

IC Ion Chromatography

$\mathrm{mM}$ milliMolar

PSAL Process Science Analytical Laboratory

SME Slurry Mix Evaporator

SRAT Sludge Receipt and Adjustment Tank

SRNL Savannah River National Laboratory 
SRNL-STI-2010-00389

Revision 0

\subsection{Introduction}

The Process Science Analytical Laboratory (PSAL) at the Savannah River National Laboratory was requested by the Defense Waste Processing Facility (DWPF) to develop and demonstrate an Ion Chromatography (IC) method for the analysis of glycolate, in addition to eight other anions (fluoride, formate, chloride, nitrite, nitrate, sulfate, oxalate and phosphate) in Sludge Receipt and Adjustment Tank (SRAT) and Slurry Mix Evaporator (SME) samples. The method will be used to analyze anions for samples generated from the Alternate Reductant Demonstrations to be performed for the DWPF at the Aiken County Technology Laboratory (ACTL). The method is specific to the characterization of anions in the simulant flowsheet work. Additional work will be needed for the analyses of anions in radiological samples by Analytical Development (AD) and DWPF. The documentation of the development and demonstration of the method fulfills the third requirement in the TTQAP, SRNL-RP-2010-00105, "Task Technical and Quality Assurance Plan for Glycolic-Formic Acid Flowsheet Development, Definition and Demonstrations Tasks 1-3”.

\subsection{IC Method}

\subsection{Instrumentation}

A Dionex DX500 IC was used to develop the method. The DX500 consists of a CD20 Conductivity Detector, GP40 Gradient Pump and a LC20 Chromatography Enclosure. An AS40 Autosampler was used and the instrument was controlled using PeakNet (version 6.4) software.

\subsection{Method Components}

The components of the IC that were considered for developing a method on the DX500 IC system were:

1. Column Type

2. Isocratic vs. Gradient Run

3. Eluent Concentration

4. Eluent Flow Rate

5. Standard bore vs. Microbore columns

6. Size of Sample Injection Loop

7. Standard Concentrations

\subsection{Analytical Columns}

Dionex provides a wide variety of hydroxide and carbonate columns for the analysis of inorganic and organic anions. There are a number of columns that could provide the necessary peak separation for the nine anions. For hydroxide compatible columns, these would include the AS11, AS14A, AS15, AS18 and AS24 columns. For carbonate compatible columns, a potential column is the AS14 column. Boyd Weidenman, Analytical Development, used Dionex's Virtual Column Software package to model each column's peak separation abilities of the first three anions (fluoride, glycolate and formate) using known retention data and IC-specific retention algorithms. Results showed that the best and quickest separation of the three anions occurs on the AS11 and AS24 columns. The AG11HC guard and AS11HC analytical columns were chosen to perform 
the method development due to the Virtual Column's chromatogram demonstration, column history in our lab and the customer's experience with the columns. High Capacity (HC) columns were used to eliminate overload on the column's sites and to decrease peak broadening. The AG11HC and AS11HC columns are specifically designed to resolve a large number of inorganic and organic anions.

\subsection{Method Development}

Method development consisted of testing isocratic or gradient runs, varying eluent concentration, flow rates, and whether to use standard or microbore columns.

IC methods are run by pumping the mobile phase through the columns at either a constant concentration (isocratic) or ramping the eluent concentration (gradient) to a desired molarity. Eluents were prepared by degassing a $60 \mathrm{mM} \mathrm{NaOH}$ solution (eluent bottle A) and 18 megaohm deionized water (eluent bottle B). Eluent concentrations were changed by mixing the eluent bottles A and B with a gradient mixer prior to sending the eluent to the column. Degassing of the eluent was performed by placing the eluent under vacuum. Degassing was necessary to remove $\mathrm{CO}_{3}{ }^{2}$ which is due to absorbed $\mathrm{CO}_{2}$ from the atmosphere. Carbonate is an interference eluting near the $\mathrm{NO}_{3}$ and $\mathrm{SO}_{4}$ peaks.

Due to the hydrophilic nature of the monovalent anions (i.e. fluoride, glycolate and formate), it was quickly determined that an isocratic run was not going to be possible. An isocratic run with the lab's typical eluent concentration of $30 \mathrm{mM} \mathrm{NaOH}$ provided no peak separation for fluoride, glycolate and formate. An isocratic run with an eluent concentration of $1.8 \mathrm{mM} \mathrm{NaOH}$ provided very good separation, but eluting all nine anions would take hours.

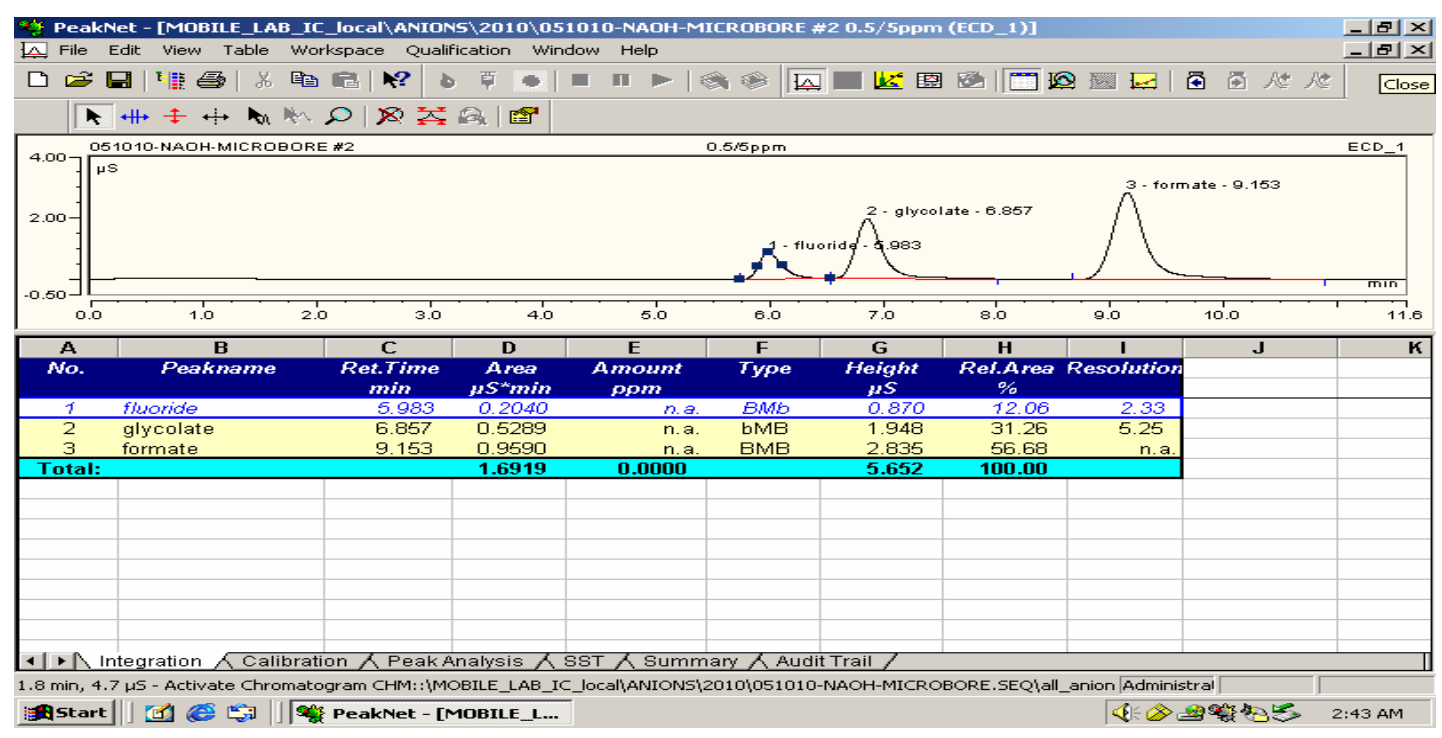

Figure 2.4-1 1.8mM NaOH - Isocratic Run

Gradient methods were then attempted using two method strategies. One attempt was to keep the eluent concentration constant for a period of time and then ramp the eluent concentration in stages. After an extensive number of tries to separate all nine peaks, the first gradient method was successful. The first gradient method was run as shown in Table 2-1 
SRNL-STI-2010-00389

Revision 0

Table 2-1 Initial Successful Gradient Method

\begin{tabular}{|c|c|}
\hline$\frac{\text { Concentration }}{\mathbf{( N a O H})}$ & $\underline{\text { Time }}$ \\
\hline $1.8 \mathrm{mM}$ & $0-10$ minutes \\
\hline $16 \mathrm{mM}$ & $10-26$ minutes \\
\hline $36 \mathrm{mM}$ & $26-40$ minutes \\
\hline $2 \mathrm{mM}$ & $40-50$ minutes \\
\hline
\end{tabular}

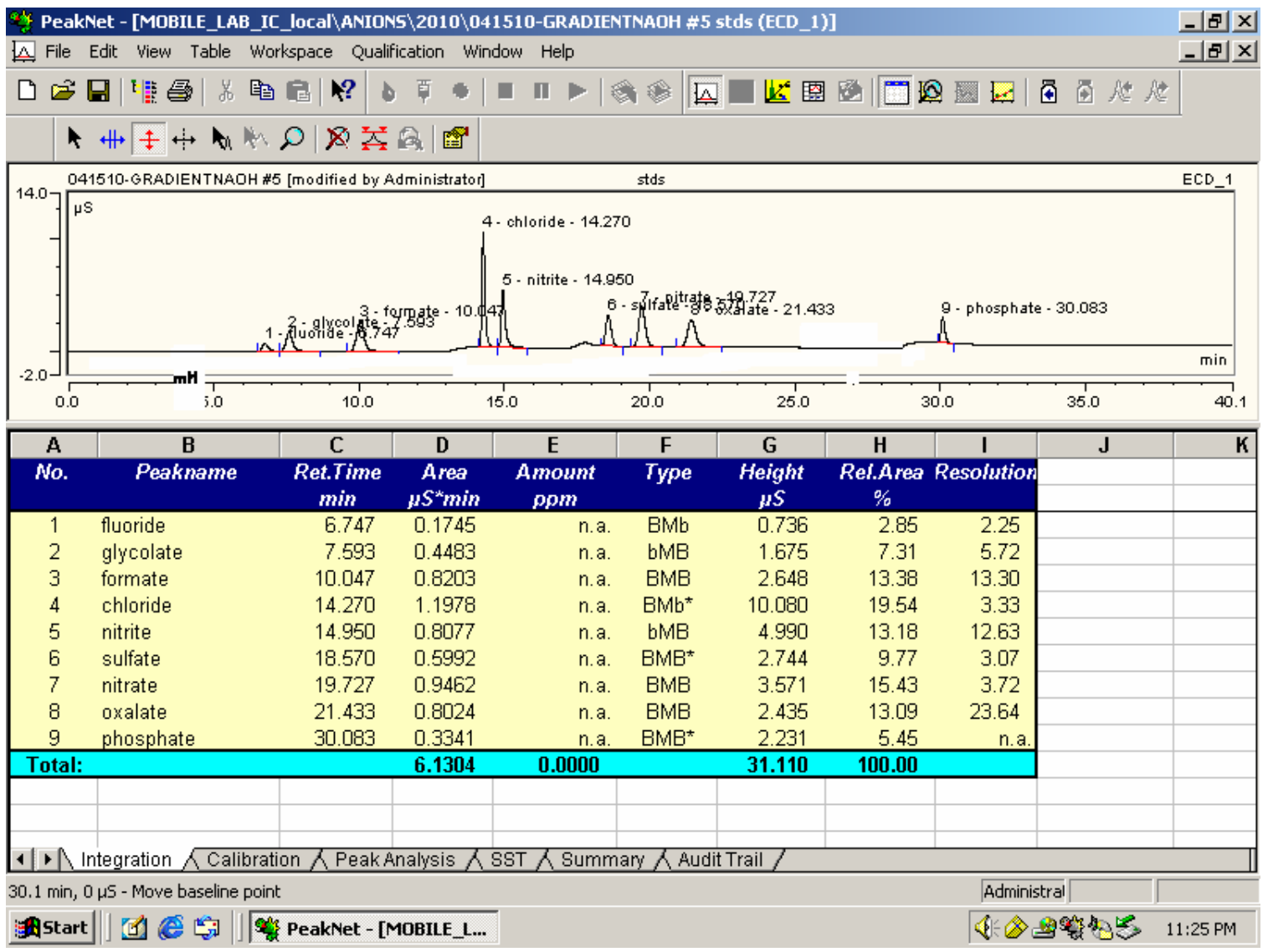

Figure 2.4-2 Gradient Method 1 - Ramped in Stages

The gradient method was successful, but after a week of running, peaks began to drift which produced poor peak separation. Peaks were also eluting on the baseline curve when ramping of eluent concentration was occurring. Both were producing poor results. The sudden drift in peak integration time may have been from buildup of $\mathrm{CO}_{3}{ }^{2}$ on the columns or inconsistent gradient mixing of the two different strength eluents.

Due to the sudden poor peak separation and the length in time which analyses were taking, a decision was made to try the AG11HC and AS11HC, 2mm microbore columns. Per Dionex, these columns can often provide better peak separation, better peak resolution and shorter run 
times. These columns also use significantly less eluent, allowing the IC to run non-stop (i.e. weekends).

A microbore system was set up consisting of a guard column (AG11HC, 2mm), analytical column (AS11HC, 2mm), a carbonate removal device (CRD-20, 2mm) and suppressor (ASRS$300,2 \mathrm{~mm}$ ). The microbore system required changing all tubing to a 0.005 inch diameter PEEK tubing. Injection loops for a $2 \mathrm{~mm}$ system are normally $<15 \mu \mathrm{l}$, flow rate $<0.75 \mathrm{ml}$ and a maximum back pressure of $<1950$ psi.

An extensive number of gradient runs were performed on this column to determine optimal performance to separate all nine anions. A ramping gradient run was used in which the eluent was increased in increments of approximately $1 \mathrm{mmol} /$ minute for various lengths of time. The following gradient method was determined to provide good peak separation for all nine anions.

Table 2-2 Successful Microbore Gradient Method

\begin{tabular}{|c|c|}
\hline$\underline{\text { Concentration (NaOH) }}$ & Time \\
\hline $1.8 \mathrm{mM} \rightarrow 30 \mathrm{mM}$ Ramp & $0-40$ minutes \\
\hline $30 \mathrm{mM} \rightarrow 1.8 \mathrm{mM}$ Ramp & $40-50$ minutes \\
\hline
\end{tabular}

A flow rate of $0.38 \mathrm{ml} / \mathrm{min}$ was used and the conductivity detector set at 50milliamps.

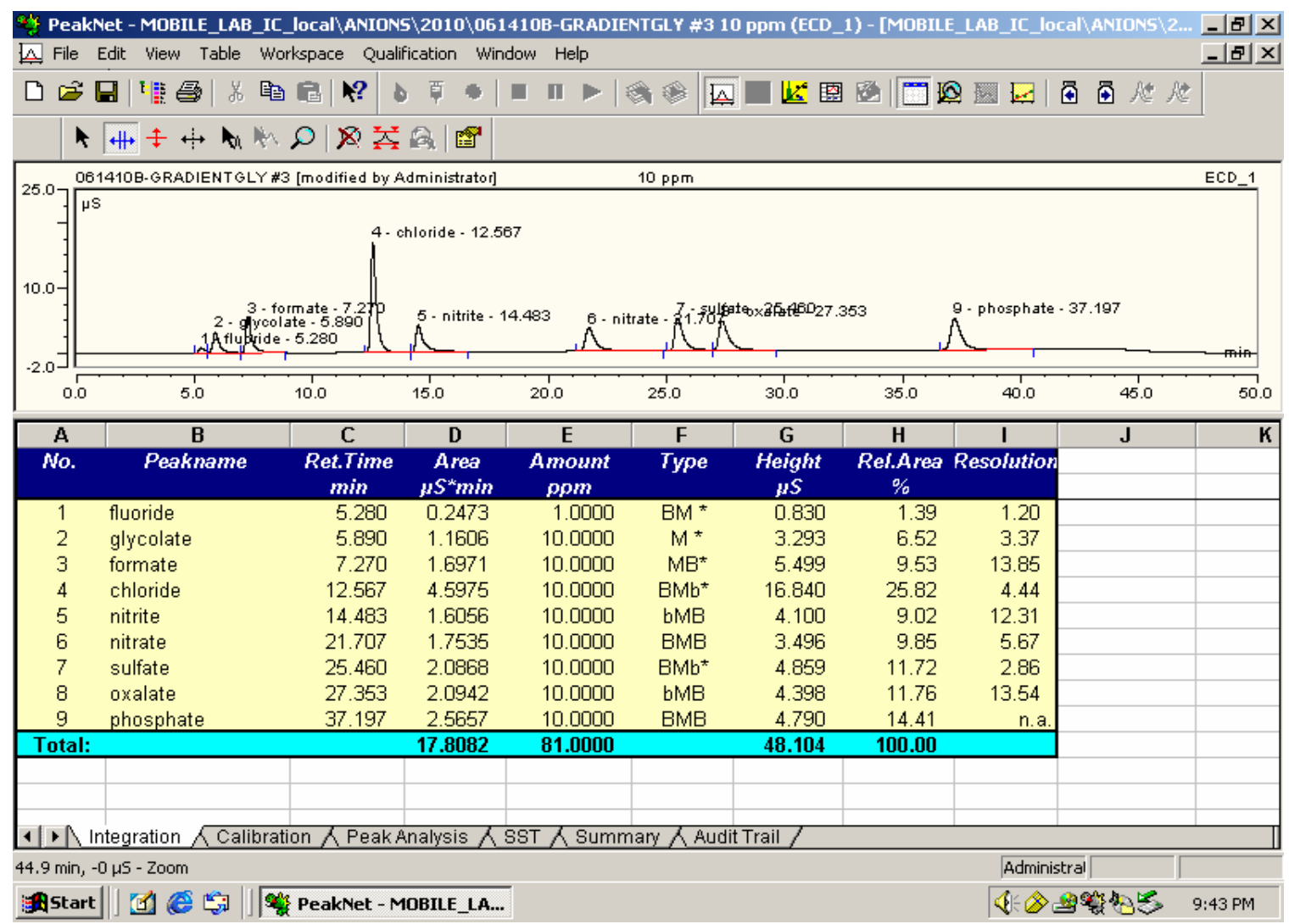

Figure 2.4-3 Gradient Method 2 - Microbore System - Ramped Increments 
The second gradient method provided good peak separation for the hydrophilic anions (fluoride, glycolate and formate) and successful peak separation for the remaining monovalent, divalent and trivalent anions that followed. However, run time did not decrease.

\subsection{Calibration}

A typical calibration for past IC analyses using the DX500 has been a $1 \mathrm{ppm}, 5 \mathrm{ppm}$ and $10 \mathrm{ppm}$ calibration curve. Due to the potential interference of fluoride with glycolate, fluoride was calibrated 10X less than glycolate or $0.1 \mathrm{ppm}, 0.5 \mathrm{ppm}$ and $1 \mathrm{ppm}$. An injection loop of 10 microliters was used. Poor peak resolution was obtained on the $1 \mathrm{ppm}$ standards and good calibration curves could not be obtained. A calibration using 5 ppm, 10 ppm, 20 ppm and 40 ppm standard was performed and good calibration curves were obtained. However, concentrations of the check standards during runs drifted high and for reasons unknown at this time, anion results showed poor linearity depending where the dilution placed the anion on the calibration curve. A second attempt to calibrate at the $1 \mathrm{ppm}, 5 \mathrm{ppm}$ and $10 \mathrm{ppm}$ concentrations was made using a larger injection loop of 25 microliters. The increase in sample size provided very good peak resolution and excellent linear calibration curves. Calibration standards were stable at the $5 \mathrm{ppm}$ level over a 24 hour time period. Note: A 1000 ppm stock calibration standards for glycolate can be obtained from Fisher Scientific, Part No.AT37054.

\subsection{Method Verification}

The gradient method using the AG11HC and AS11HC, 2mm microbore columns was compared to the isocratic AG11HC and AS11HC, 4mm column that PSAL has used on the DX500 for years. A SB6 SRAT sample was obtained and anions run on the gradient method and compared with an isocratic run made several months ago on the same sample. Results were within $10 \%$ of the methods. Formate was lower on the gradient run, but was probably a result of degradation of formate in the sample over time.

Table 2-3 Anion Verification - Isocratic vs. Gradient

\begin{tabular}{|c|c|c|c|c|c|c|c|c|}
\hline Units: $\mathrm{mg} / \mathrm{Kg}$ & \multicolumn{8}{|c|}{ Isocratic Method } \\
\hline Sample ID & $\underline{\text { Lab ID }}$ & $\underline{F}$ & $\underline{\mathrm{Cl}}$ & NO2 & $\underline{\mathrm{NO} 3}$ & $\underline{\mathrm{SO} 4}$ & $\underline{\mathrm{HCO} 2}$ & $\underline{\mathrm{C} 2 \mathrm{O} 4}$ \\
\hline SB6-19/20-3108 (A) & $10-0012$ & $<100$ & 257 & $<100$ & 33900 & 129 & 65400 & $<100$ \\
\hline SB6-19/20-3108 (B) & $10-0012$ & $<100$ & 254 & $<100$ & 34100 & 148 & 64800 & $<100$ \\
\hline Units: $\mathbf{m g} / \mathrm{Kg}$ & \multicolumn{8}{|c|}{ Gradient Method - Gradient Method } \\
\hline$\underline{\text { Sample ID }}$ & Lab ID & $\underline{F}$ & $\underline{\mathrm{Cl}}$ & $\underline{\mathrm{NO} 2}$ & $\underline{\mathrm{NO3}}$ & $\underline{\mathrm{SO} 4}$ & $\underline{\mathrm{HCO} 2}$ & $\underline{\mathrm{C} 2 \mathrm{O} 4}$ \\
\hline SB6-19/20-3108 (A) & $10-0012$ & $<100$ & 285 & $<100$ & 33600 & $<100$ & 60200 & $<100$ \\
\hline SB6-19/20-3108 (B) & $10-0012$ & $<100$ & 283 & $<100$ & 33600 & $<100$ & 60700 & $<100$ \\
\hline
\end{tabular}

Another SB6 sample was obtained at a later date during method development and the sample was spiked with $10 \mathrm{ppm}$ glycolate. A recovery of $9.96 \mathrm{ppm}$ was obtained. The results for the glycolate spike are shown in Table 2-4. 
Table 2-4 Glycolate Spike

\begin{tabular}{|c|c|c|c|}
\hline \multirow[t]{2}{*}{ Units: $\mathrm{mg} / \mathrm{Kg}$} & \multicolumn{3}{|c|}{ Gradient Method - Gradient Method (No Glycolate Spike) } \\
\hline & NO3 & $\underline{\mathrm{HCO} 2}$ & \\
\hline SB6-19/20 & 33500 & 53800 & \\
\hline \multirow[t]{2}{*}{ Units: $\mathbf{m g} / \mathrm{Kg}$} & \multicolumn{3}{|c|}{ Gradient Method - Gradient Method (10 ppm Glycolate Spike) } \\
\hline & $\underline{\mathrm{NO} 3}$ & $\underline{\mathrm{HCO} 2}$ & $\mathrm{C} 2 \mathrm{H} 3 \mathrm{O} 3$ \\
\hline SB6-19/20 & 34200 & 56000 & 9.96 \\
\hline
\end{tabular}

\subsection{Sample Runs}

Samples for the Alternative Reductant Demonstrations were analyzed by diluting the SRAT/SME samples by a factor of $10,000 \mathrm{X}$ and $500 \mathrm{X}$. These dilutions placed the results within the calibration curve of $1 \mathrm{ppm}, 5 \mathrm{ppm}$ and $10 \mathrm{ppm}$. Even with high levels of glycolate at the $500 \mathrm{X}$ dilution, there was still good peak separation between formate and glycolate, allowing for accurate analysis of formate. The high levels of nitrate at the $500 \mathrm{X}$ dilution also did not create any interferences.

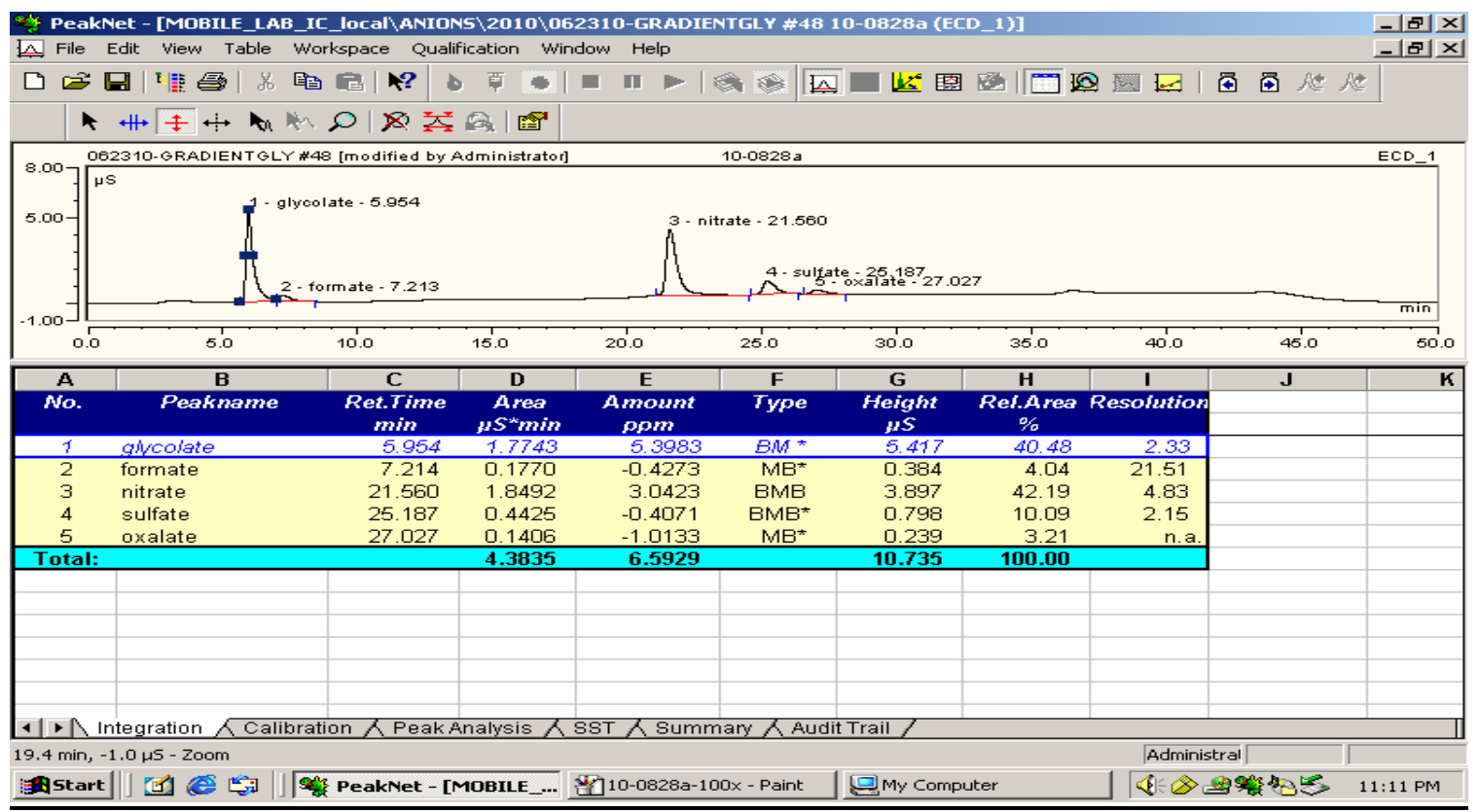

Figure 2.7-1 10000X Dilution - Glycolic/Formic Run 6 


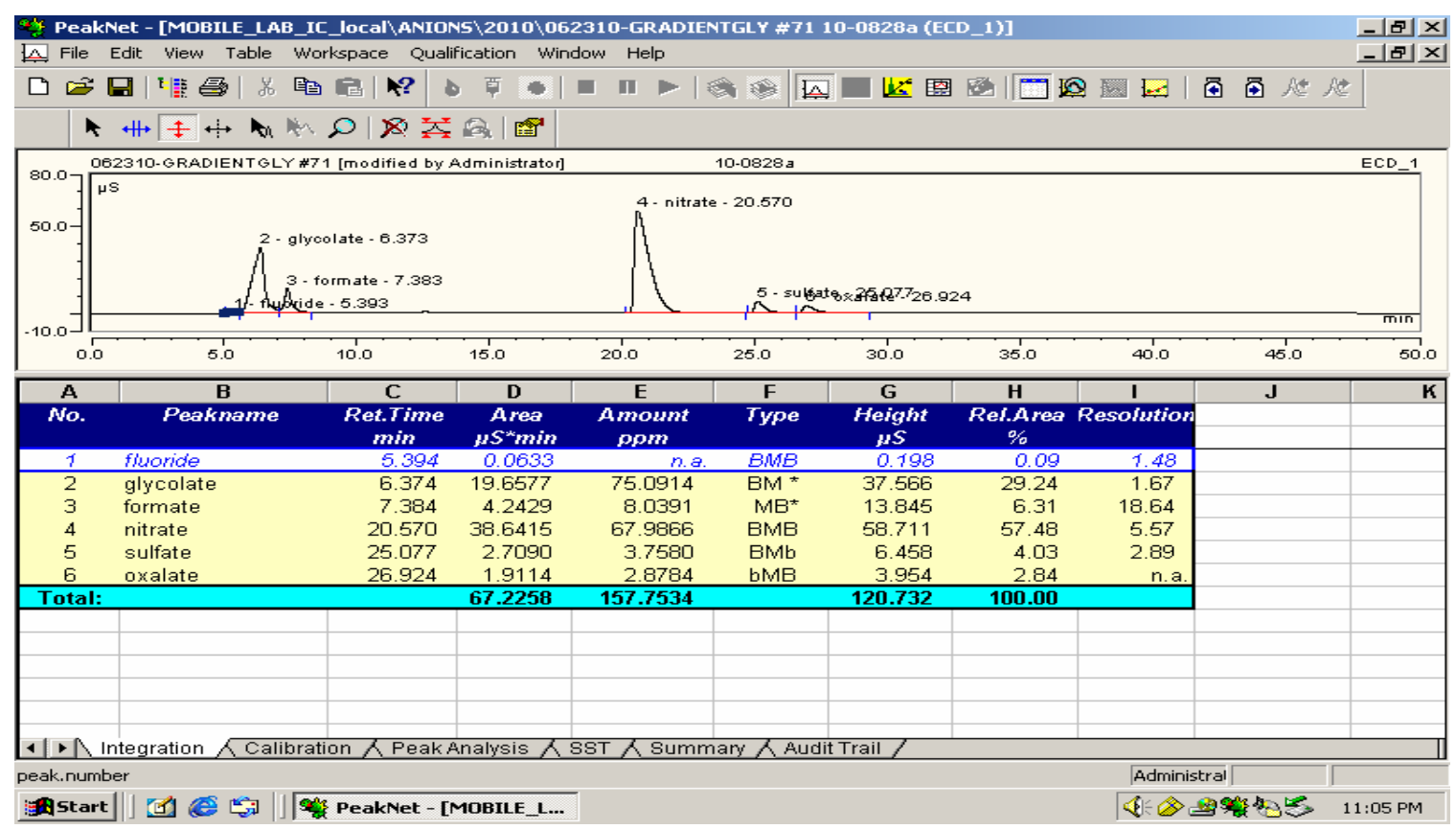

Figure 2.7-2 500X Dilution - Glycolic/Formic Run 6

\subsection{Conclusions}

A successful gradient method using the AG-11HC and AS-11HC, 2mm microbore columns was developed to run samples for the Alternative Reductant Demonstrations. The method provides good peak resolution for all nine anions. The method that will be used to analyze fluoride, glycolate, formate, chloride, nitrite, nitrate, sulfate, oxalate and phosphate on SRAT/SME samples is as follows:

Table 3-1 Final Ion Chromatography Method for Glycolate and Other Anions

\begin{tabular}{|c|c|}
\hline Instrument - & DX500 \\
\hline Columns - & 2mm AG-11HC, 2mm AS-11HC \\
\hline Suppressor - & ASRS-300, 2mm \\
\hline Carbonate Removal Device - & CRD-20, 2mm \\
\hline Injection Loop - & 25 microliter \\
\hline Calibration Standards - & $\begin{array}{l}\text { Three point calibration ( } 0.1,0.5,1 \mathrm{ppm} \\
\text { fluoride, } 1,5,10 \mathrm{ppm} \text { for all other anions) }\end{array}$ \\
\hline $\begin{array}{l}\text { Gradient Run, Concentration } \\
\text { (NaOH) }\end{array}$ & Time \\
\hline $1.8 \mathrm{mM} \rightarrow 30 \mathrm{mM}$ Ramp & 0-40 minutes \\
\hline 30mM $\rightarrow$ 1.8mM Ramp & 40-50 minutes \\
\hline Detection Limit & Lowest calibration standard \\
\hline
\end{tabular}




\subsection{Recommendations}

Organic anions at low concentrations (1 ppm, 5 ppm, $10 \mathrm{ppm}$ ) degrade over a short period of time. Due to the potential degradation, it is our recommendation to keep all organic anion standards (manufacturer and calibration) refrigerated and in the dark. New calibration standards should be made every time the instrument is calibrated.

The run time is significantly long due to the request for phosphate. The stability of phosphate when analyzing SRAT and SME samples is extremely sensitive due to the high transition metals (i.e. iron) that build up in the columns. Phosphate has a tendency to bind with the transition metals creating erroneous readings. Also, the transition metals can create peak tailing. This often creates poor accuracy of calibrations check standards at the end of sample runs. Phosphate is never above detection limit of the IC for typical SRAT/SME samples and is reported as a less than value. A recommendation is to obtain phosphorus by ICP-AES and remove phosphate from the list of requested anions. This could decrease run time significantly.

Another solution to significantly decrease run time is for DWPF to purchase a new ICS-5000 system that could run multiple methods simultaneously on one sample injection. For example, one method could be set up to elute the first three anions (fluoride, formate and glycolate) slowly off the column to obtain results and another method run to quickly elute these three anions off the column (no peak separation obtained) and then get good separation for the other six anions in 1020 minutes. The same solution could be obtained on DWPF's two ICS-3000 systems.

The potential of fluoride interfering with glycolate can be a problem. Over time, baseline peak separation can diminish and a large fluoride peak in the calibration standards can create error in the glycolate analyses, if fluoride is not present. Fluoride in SRAT/SME samples is always below detection. A recommendation is to eliminate this peak to decrease the potential analytical error with glycolate.

\subsection{Path Forward}

PSAL will be setting up a new Dionex ICS-5000 within the next six months. The ICS-5000 system is a capillary reagent-free ion chromatography system that according to literature will provide shorter run times and superior peak resolution. Computer-controlled delivery of eluent will be precise. There are only a select set of columns to choose from at this time, so another method will have to be developed.

Method development could continue on the DX500 system to decrease run time. Two columns that could be evaluated for shorter run times are the AS14A and AS24 hydroxide columns. The virtual software package for the AS24, 2mm column showed that fluoride, glycolate and formate can be separated in six minutes using a gradient method with a start of $10 \mathrm{mM} \mathrm{NaOH}$. Dionex also has demonstrated that the AS14A, 2mm is capable of running all nine anions using a gradient run of $\mathrm{KOH}$, ramping from $5 \mathrm{mM}$ to $80 \mathrm{mM}$ in 20 minutes.

If radiological runs are performed on this campaign, PSAL will assist in developing a method with Analytical Development on their ICS-3000 system. 


\subsection{Acknowledgements}

I would like to thank Whitney Riley, PSAL for assistance in running the IC during developmental of the method. PSAL would also like to thank Boyd Weidenman for his assistance in using Dionex’s Virtual Column Software to look at potential columns for the analytical work. 


\section{Distribution:}
A. B. Barnes, 999-W
D. A. Crowley, 773-43A
S. D. Fink, 773-A
B. J. Giddings, 786-5A
C. C. Herman, 999-W
S. L. Marra, 773-A
F. M. Pennebaker, 773-42A
C. J. Bannochie, 773-42A
P. L. Bovan, 704-27S
J. F. Iaukea, 704-30S
D. D. Larsen, 766-H
R. T. McNew, 704-27S
J. E. Occhipinti, 704-S
D. K. Peeler, 999-W
J. W. Ray, 704-S
D. C. Sherburne, 704-S
M. E. Stone, 999-W
M. A. Broome, 704-29S
R. N. Hinds, 704-S
J. P. Vaughan, 773-41A

J. M. Bricker, 704-27S

T. L. Fellinger, 704-26S

E. W. Holtzscheiter, 704-15S

M. T. Keefer, 766-H

M.T. Feller, 704-28S

R.N. Mahannah, 704-28S

B.J. Weidenman, 773-A

C. L. Gregory, 773-A

M. J. Hart, 210-S 